\title{
Erratum to: Synthesis, characterization, and biological evaluation of new oxime-phosphazenes
}

\author{
Kenan Koran • Ahmet Ozkaya • Furkan Ozen • \\ Erol Cil · Mustafa Arslan
}

Published online: 11 May 2013

(C) Springer Science+Business Media Dordrecht 2013

\section{Erratum to: Res Chem Intermed (2013) 39:1109-1124 DOI 10.1007/s11164-012-0670-2}

We have discerned that, in our work, one of the authors made mistakes in the biological result tables (Tables 1, 2). Because discussions and conclusions were made by evaluation of data that was presented in these tables, the discussions and conclusions, abstract, and sections of the article also contain mistakes. We apologise to the Publisher, scientific world, Editorial Board of Research on Chemical Intermediates, and all readers for these great mistakes. The tables, and the related parts of abstract, discussions and conclusions sections of the article are corrected in this erratum.

Tables 1 and 2 are corrected as below:

The online version of the original article can be found under doi:10.1007/s11164-012-0670-2.

K. Koran · F. Ozen

Chemistry Department, Science Faculty, Firat University, 23169 Elazig, Turkey

A. Ozkaya

Biochemistry Department, Science Faculty, Adiyaman University, 02040 Adiyaman, Turkey

E. Cil $(\bowtie)$

Science Education Department, Education Faculty, Firat University, 23169 Elazig, Turkey

e-mail: cilerol@yahoo.com

M. Arslan

Science Education Department, Education Faculty, Yildiz Technical University, Istanbul, Turkey 
Table 1 Antibacterial and antifungal activity of the synthesized compounds-in vitro activity zone of inhibition in $\mathrm{mm}$

\begin{tabular}{|c|c|c|c|c|c|c|}
\hline \multirow[t]{2}{*}{ Compd. No. } & \multicolumn{2}{|c|}{ Gram-positive } & \multicolumn{2}{|c|}{ Gram-negative } & \multicolumn{2}{|l|}{ Fungi } \\
\hline & S. aureus & E. faecalis & E. coli & K. pneuтопіа & A. niger & C. albicans \\
\hline 2 & 14 & 11 & 13 & 16 & 6 & 9 \\
\hline 3 & 13 & 14 & 14 & 16 & 8 & 8 \\
\hline 4 & 15 & 13 & 14 & 14 & 9 & 9 \\
\hline 5 & 18 & 17 & 17 & 19 & 3 & 5 \\
\hline 6 & 12 & 15 & 15 & 15 & 9 & 9 \\
\hline 7 & 26 & 27 & 25 & 27 & 18 & 17 \\
\hline 8 & 21 & 18 & 20 & 17 & 4 & 7 \\
\hline 9 & 26 & 25 & 23 & 24 & 7 & 10 \\
\hline 10 & 28 & 28 & 26 & 27 & 17 & 18 \\
\hline 11 & 17 & 20 & 18 & 19 & 8 & 5 \\
\hline 12 & 14 & 12 & 13 & 16 & 8 & 9 \\
\hline 13 & 28 & 30 & 26 & 29 & 18 & 19 \\
\hline Ciprofloxacin & 29 & 30 & 28 & 31 & - & - \\
\hline Fluconazole & - & - & - & - & 20 & 23 \\
\hline Control & - & - & - & - & - & - \\
\hline
\end{tabular}

“-“ no activity

Table 2 Minimum inhibitory concentration $(\mu \mathrm{g} / \mathrm{mL})$

\begin{tabular}{|c|c|c|c|c|c|c|}
\hline \multirow[t]{2}{*}{ Compd. No. } & \multicolumn{2}{|c|}{ Gram-positive } & \multicolumn{2}{|c|}{ Gram-negative } & \multicolumn{2}{|l|}{ Fungi } \\
\hline & S. aureus & E. faecalis & E. coli & K. рпеитопіа & A. niger & C. albicans \\
\hline 2 & 100 & 100 & 100 & 100 & $>100$ & $>100$ \\
\hline 3 & 100 & 100 & 100 & 100 & $>100$ & $>100$ \\
\hline 4 & 100 & 100 & 100 & 100 & $>100$ & $>100$ \\
\hline 5 & 50 & 50 & 50 & 50 & $>100$ & $>100$ \\
\hline 6 & 100 & 100 & 100 & 100 & $>100$ & $>100$ \\
\hline 7 & 25 & 25 & 25 & 25 & 75 & 75 \\
\hline 8 & 50 & 50 & 50 & 50 & $>100$ & $>100$ \\
\hline 9 & 25 & 25 & 25 & 25 & $>100$ & $>100$ \\
\hline 10 & 25 & 25 & 25 & 25 & 75 & 75 \\
\hline 11 & 50 & 50 & 50 & 50 & $>100$ & $>100$ \\
\hline 12 & 100 & 100 & 100 & 100 & $>100$ & $>100$ \\
\hline 13 & 25 & 25 & 25 & 25 & 75 & 75 \\
\hline Ciprofloxacin & 12.5 & 12.5 & 12.5 & 12.5 & - & - \\
\hline Fluconazole & - & - & - & - & 12.5 & 12.5 \\
\hline
\end{tabular}

"_" no activity 
The last sentence of the abstract should be corrected as follows:

"None of the compounds had antifungal activity except compounds 7, 10 and 13 which showed moderate activity."

The last paragraph of the Result and Discussion section (starting with 9th sentence of paragraph) should be corrected as follows:

"Compounds 7, 9, 10, which contain benzoyl group, and compound 13, which contains thiophene ring, had significant activity against all four microorganisms, with inhibition zones ranging between 23 and $30 \mathrm{~mm}$ at $25 \mu \mathrm{g} / \mathrm{mL}$. Compounds 5,8 and 11, which contain carbonyl group, had moderate activity, with inhibition zones ranging between 17 and $21 \mathrm{~mm}$ at $50 \mu \mathrm{g} / \mathrm{mL}$. Compounds 2, 3, 4, 6 and 12 had least activity, with inhibition zones of $11-16 \mathrm{~mm}$ at $100 \mu \mathrm{g} / \mathrm{mL}$. The in-vitro antifungal evaluation revealed that the activity of all the compounds was relatively weak compared to their antibacterial activity. Unexpectedly, all target compounds had negative efficacy except compounds $7, \mathbf{1 0}$ and 13 which had moderate activity. In general, the compounds had better antibacterial than antifungal activity."

The third and fourth sentences of the Conclusion section should be corrected as follows:

"The thiophene ring in compound $\mathbf{1 3}$ and the benzoyl group in the compounds $\mathbf{7 ,}$ 9, and $\mathbf{1 0}$ had a positive effect on antibacterial effectiveness which resulted in better antibacterial activities against all four bacterial pathogens than all the other compounds. Compound 2, which does not contain an oxime group, and compounds 3, 4, 6 and 12, which do not contain carbonyl group, were least active (active at $100 \mu \mathrm{g} / \mathrm{mL}$ only)." 